\title{
Геоэкология городских озер Мурманска
}

\author{
Даувальтер В.А. ${ }^{1}$, Слуковский 3.И., ${ }^{1,2}$, Денисов Д.Б. ${ }^{1}$, Черепанов А.А. ${ }^{1}$ \\ ${ }^{1}$ Институт проблем промышиенной экологии Севера КНЦ РАН, Anamumbl,v.dauvalter@ksc.ru \\ ${ }^{2}$ Институт геологии Карельского НЦ РАН, Петрозаводск, slukovsky87@gmail.com
}

\begin{abstract}
Аннотация. Предоставлены результаты исследований гидрохимического состава пяти озер г. Мурманска. Установлено, что химический состав воды исследуемых городских озер существенно отличается от состава озер северо-восточной части Мурманской области водосбора Баренцева моря. Увеличились значения рН воды по сравнению с фоновыми значениями, минерализация, содержание главных ионов, биогенных элементов и тяжелых металлов. Вследствие поступления морских аэрозолей в водах городских озер повышено содержание щелочных ( $\mathrm{Li}$ и $\mathrm{Rb}$ ) и щелочноземельных ( $\mathrm{Sr}$ и $\mathrm{Ba}$ ) металлов, а также В и Вr. Значительно увеличилось содержание соединений азотной группы, особенно аммоний-иона. Наиболее загрязненным среди исследованных водоемов является оз. Ледовое, характеризующееся наибольшим содержанием вышеперечисленных показателей, а также многих тяжелых металлов ( $\mathrm{Ni}, \mathrm{Cu} \mathrm{Zn}, \mathrm{Co}, \mathrm{As}, \mathrm{Mo} \mathrm{и} \mathrm{W).}$
\end{abstract}

Ключевые слова: гидрохимия, городские озера, тяжелые металлы, загрязнение, Мурманская область.

\section{Features of the chemical composition of water in the urban lakes of Murmansk}

\author{
Dauvalter V.A. ${ }^{1}$, Slukovskii Z.I. ${ }^{1,2}$, Denisov D.B. ${ }^{1}$, Cherepanov A.A. ${ }^{1}$ \\ ${ }^{1}$ Institute of North Industrial Ecology Problems Kola SC RAS, Apatity,v.dauvalter@ksc.ru \\ ${ }^{2}$ Geological institute Karelia SC RAS, Petrozavodsk, slukovsky87@gmail.com
}

\begin{abstract}
The article presents the results of studies of the hydrochemical composition of five urban lakes of Murmansk. It was found that the chemical composition of the water of the studied urban lakes is significantly different from the composition of the lakes of the north-eastern part of the Murmansk region of the Barents Sea catchment. The water $\mathrm{pH}$ values have increased comparing with the background values, as well as mineralization, the content of major ions, nutrients and heavy metals. Due to the influx of marine aerosols in the waters of urban lakes, the content of alkaline ( $\mathrm{Li}$ and $\mathrm{Rb}$ ) and alkaline-earth $(\mathrm{Sr}$ and $\mathrm{Ba}$ ) metals, as well as $\mathrm{B}$ and $\mathrm{Br}$, is increased. The content of compounds of the nitrogen group, especially the ammonium ion, significantly increased in the water of urban lakes. Lake Ledovoe is the most polluted among the studied lakes, characterized by the highest content of the above mentioned indicators, as well as many heavy metals ( $\mathrm{Ni}, \mathrm{Cu} \mathrm{Zn}, \mathrm{Co}, \mathrm{As}$, Mo and $\mathrm{W}$ ).
\end{abstract}

Key words: hydrochemistry, urban lakes, heavy metals, pollution, Murmansk Region.

\section{Введение}

Основными источниками загрязнения Мурманска являются выбросы Мурманской ТЭЦ и автотранспорта, пыль, образующаяся при погрузке-разгрузке угля, апатитового концентрата и других грузов в Мурманском морском торговом порте. Мурманская ТЭЦ была введена в эксплуатацию в 1934 г. и использовала уголь в качестве основного источника топлива до 1964 г. В 1960-е годы начался постепенный перевод Мурманской ТЭЦ на новый вид топлива - мазут. Выбросы предприятий Кольской горно-металлургической компании, перерабатывающие сульфидные медно-никелевые руды, также являются источником поступления цветных металлов и оксидов серы на водосборы водоемов Мурманска. Еще одним источником загрязнения окружающей среды является трансграничный перенос на большие расстояния различных загрязнителей, таких как $\mathrm{Pb}, \mathrm{As}, \mathrm{Hg}, \mathrm{Cd}, \mathrm{Sb}$ и $\mathrm{Bi}$ из других стран. Специальных исследований водных объектов городской среды в арктической зоне, характеризующиеся высокой чувствительности экосистем к воздействию человека и малыми темпами естественного восстановления после их загрязнения и повреждения, проводится очень мало. Целью данного исследования является изучение гидрохимического состава и оценка геоэкологического состояния пяти озер Мурманска. 


\section{Материалы и методы}

Мурманск является одним из крупнейших портов за Полярным кругом и вторым портом (после Санкт-Петербурга) на северо-западе России. Для оценки воздействия городской среды на экосистемы озер для исследования было выбрано 5 озер (табл. 1), расположенных в разных частях г. Мурманска, в различной степени подверженных влиянию антропогенной деятельности и имеющих большую рекреационную значимость для жителей и гостей города. Все изученные озера находятся на водосборе Баренцева моря.

Таблица 1. Основные морфометрические характеристики озер Мурманска.

Table 1. Main morphometric characteristics of lakes in the Murmansk Region.

\begin{tabular}{|c|c|c|c|c|c|}
\hline \multirow{2}{*}{ Озеро } & \multicolumn{2}{|c|}{ Координаты отбора проб } & \multirow{2}{*}{$\begin{array}{c}\text { Отметка уреза } \\
\text { воды, м }\end{array}$} & \multirow{2}{*}{$\begin{array}{l}\text { Площадь } \\
\text { озера, км² }\end{array}$} & \multirow{2}{*}{$\begin{array}{c}\text { Максимальная } \\
\text { глубина, м }\end{array}$} \\
\hline & Северная широта & Восточная долгота & & & \\
\hline Семеновское & $68^{\circ} 59^{\prime} 27.52 »$ & $33^{\circ} 05^{\prime} 18.28 »$ & 98 & 0.213 & 11.3 \\
\hline Среднее & $68^{\circ} 58^{\prime} 50.08 »$ & $33^{\circ} 07^{\prime} 27.60 »$ & 111 & 0.248 & 23.5 \\
\hline Окуневое & $68^{\circ} 57^{\prime} 04.49 »$ & $33^{\circ} 07^{\prime} 47.76 »$ & 119 & 0.048 & 5.6 \\
\hline Ледовое & $68^{\circ} 55^{\prime} 58.56 »$ & $33^{\circ} 06^{\prime} 21.81 »$ & 80 & 0.040 & 15.7 \\
\hline Южное & $68^{\circ} 53^{\prime} 03.99_{» »}$ & $33^{\circ} 04^{\prime} 31.00 »$ & 90 & 0.053 & 11.3 \\
\hline
\end{tabular}

Пробы воды с поверхностного слоя (1 м от поверхности) и придонного слоя (1 м от дна) озер отбирались 2-х литровым пластиковым батометром в весенне-летний период 2018-2019 гг. Химический состав воды определяли в центре коллективного пользования ИППЭС Кольского НЦ РАН и в ИГ Карельского НЦ РАН по единым методикам. Результаты химического анализа воды с каждой станции усреднялись, и в дальнейшем интерпретация результатов проводилась с учетом усредненных данных.

\section{Результаты и обсуждение}

Для природных вод Кольского Севера характерна низкая минерализация 20-30 мг/л и следующий порядок распределения главных ионов: $\mathrm{HCO}_{3}>\mathrm{SO}_{4}^{2-}>\mathrm{Cl}^{-} ; \mathrm{Ca}^{2+}>\mathrm{Na}^{+}>\mathrm{Mg}^{2+}>\mathrm{K}^{+}$(Моисеенко и др., 2002). В озерах, распложенных вблизи Баренцева моря, вследствие влияния морских аэрозолей Баренцева моря, основные ионы по величинам распределяются следующим образом: $\mathrm{Cl}^{-}>\mathrm{HCO}_{3}>\mathrm{SO}_{4}{ }^{2-} ; \mathrm{Na}^{+}>\mathrm{Ca}^{2+}>\mathrm{Mg}^{2+}>\mathrm{K}^{+}$(Кашулин и др., 2010). Медианное значение $\mathrm{pH}$ воды находится на границе между слабокислым и нейтральным - 6.5.

Значение рН воды озер г. Мурманска находится в пределах от 6.6 до 9.34. Максимальные значения отмечены в оз. Ледовое. Высокие величины рН воды отмечены в оз. Южное, что относится к щелочным и слабощелочным условиям. Воды остальных озер характеризуются нейтральными значениями величины $\mathrm{pH}$ (табл. 2). Максимальные значения минерализации воды зафиксированы в оз. Ледовое. На втором месте по минерализации стоит оз. Южное. Минерализация воды в этих озерах в десятки раз превышает величины, зафиксированные в фоновых озерах, за которые были приняты озера северо-восточной части Мурманской области водосбора Баренцева моря (Кашулин и др., 2010). Наименьшие величины минерализации зафиксированы в озерах Окуневое и Семеновское, но они также больше минерализации в фоновых озерах. Увеличение содержания главных катионов щелочных и щелочноземельных металлов $\left(\mathrm{Ca}^{2+}, \mathrm{Mg}^{2+}, \mathrm{Na}^{+}\right.$и $\left.\mathrm{K}^{+}\right)$, а также главных анионов $\left(\mathrm{HCO}_{3}{ }^{-}, \mathrm{SO}_{4}{ }^{2-}, \mathrm{Cl}^{-}\right)$, может быть связано с разрушением элементов городских зданий и сооружений, а также с использованием реагентов для противогололедной обработки городских дорог. По классификации О.А. Алекина (1970) воды озер Семеновское, Ледовое и Южное относятся к хлоридному классу и натриевой группе, а озер Окуневое и Среднее к гидрокарбонатному классу и кальциевой группе, т.е. типичное для основной массы озер Мурманской области распределение главных ионов.

В воде оз. Ледовое зафиксировано максимальное содержание соединений азотной группы (аммоний-иона и общего азота), что связано с поступлением сточных вод с городской территории, а также разложением нефтепродуктов, в большом количестве захороненных в донных отложениях 
озера (табл. 2). Известно, что азот в нефтепродуктах содержится в количестве десятых долей процента (Большаков, 1988). Содержание $\mathrm{NH}_{4}^{+}$в оз. Ледовое подобно содержанию главного катиона $\mathrm{K}^{+}$ в пересчете на эквивалентную концентрацию. Максимальное содержание $\mathrm{NH}_{4}^{+}$в оз. Ледовое более чем в 300 больше среднего содержания этого иона в фоновых озерах. Содержание нитрат-иона в воде оз. Ледовое на 3 порядка меньше (табл. 2), чем аммоний-иона, что говорит о присутствии восстановительной обстановки в придонных слоях воды озера (Никаноров, 2000).

Таблица 2. Средние гидрохимические параметры Мурманских озер.

Table 2. Average hydrochemical parameters of the Murmansk lakes.

\begin{tabular}{|c|c|c|c|c|c|}
\hline \multirow{2}{*}{ Параметр, единица измерения } & \multicolumn{5}{|c|}{ Озеро } \\
\hline & Семеновское & Среднее & Окуневое & Ледовое & Южное \\
\hline $\mathrm{pH}$ & 6.82 & 7.27 & 6.88 & 7.79 & 8.42 \\
\hline $\mathrm{Ca}^{2+}, \mathrm{мг/л}$ & 8.3 & 18.8 & 9.2 & 58.3 & 31.5 \\
\hline $\mathrm{Mg}^{2+}$, мг/л & 2 & 3.9 & 2.1 & 10.3 & 8.5 \\
\hline $\mathrm{Na}^{+}$, мг/л & 10.9 & 17.8 & 6.4 & 124.4 & 45.6 \\
\hline $\mathrm{K}^{+}$, мг/л & 2.2 & 3.9 & 1.4 & 9.7 & 6.4 \\
\hline $\mathrm{HCO}_{3}^{-}, \mathrm{мг} /$ л & 22 & 43 & 20 & 196 & 116 \\
\hline $\mathrm{SO}_{4}^{2-}, \mathrm{мг/л}$ & 9.6 & 31.5 & 14.9 & 28.4 & 16.8 \\
\hline $\mathrm{Cl}^{-}, \mathrm{мг} / л$ & 17.8 & 24.7 & 8.9 & 185 & 68.9 \\
\hline Минерализация, мг/л & 73 & 143 & 63 & 612 & 294 \\
\hline $\mathrm{NH}_{4}^{+}$, мкгN/л & 187 & 30 & 24 & 3475 & 35 \\
\hline $\mathrm{NO}_{3}^{-}$, мкг $\mathrm{N} / л$ & 76 & 86.4 & 28.8 & 1.6 & 9 \\
\hline $\mathrm{N}_{\text {обш }}$, мкг $\mathrm{N} /$ л & 542 & 369 & 315 & 3711 & 275 \\
\hline $\mathrm{PO}_{4}^{3-}$, мкг Р/л & 4.6 & 0.8 & 2.25 & 37.8 & 4 \\
\hline $\mathrm{P}_{\text {обш.ф., }}$, мкГР/л & 7.2 & 3.8 & 5.5 & 47.6 & 10.3 \\
\hline $\mathrm{P}_{\text {обш.нф, }}$, мкгР/л & 34.2 & 12.8 & 13.8 & 664 & 16.7 \\
\hline Цветность, $\mathrm{Pt}^{\circ}$ & 12.6 & 8 & 53.3 & 25.4 & 10.3 \\
\hline ХПК, мг/л & 4.3 & 3.3 & 9.2 & 8 & 5.1 \\
\hline $\mathrm{C}_{\text {opr }}, \mathrm{M \Gamma C/л}$ & 4.8 & 4.1 & 8.6 & 7.7 & 5.5 \\
\hline $\mathrm{Si}, \mathrm{мг} /$ л & 0.25 & 0.2 & 0.97 & 4.72 & 0.15 \\
\hline
\end{tabular}

Максимальное содержание соединений фосфора (фосфат-иона и общего фосфора в фильтрованной и нефильтрованной воде) также отмечено в воде оз. Ледовое (табл. 2). Содержание $\mathrm{PO}_{4}^{3-}$ в придонных слоях на глубине 13 м в этом озере доходит до 65 мкгР/л, общего фосфора до 1677 мкгР/л, что на один-два порядка больше, чем среднее содержание этих компонентов (2 и 9 мкгР/л соответственно) в фоновых озерах (Кашулин и др., 2010).

Содержание органических веществ в воде исследуемых городских озер меньше, чем средние показатели в фоновых озерах (Кашулин и др., 2010) - $62 \mathrm{Pt}^{\circ}, 9.5$ мг/л и 7.7 мгС/л для цветности, ХПК и $\mathrm{C}_{\text {орг }}$ соответственно (табл. 2). Водные массы исследуемых озер формируются за счет поверхностного стока с городской территории, в меньшей степени покрытой почвенно-растительным слоем по сравнению с природными условиями, что уменьшает поступление аллохтонного органического материала.

Характерной особенностью химического состава поверхностных вод Арктической зоны и Севера России является повышенные концентрации $\mathrm{Fe}, \mathrm{Al}, \mathrm{Mn}$ вследствие гумификации водосборов (Моисеенко и др., 2013). В воде оз. Окуневое зафиксировано наибольшее содержание Fe (табл. 3), также как и наибольшее содержание органического материала, что может свидетельствовать о преобладающем нахождении $\mathrm{Fe}$ в составе коллоидных органических соединений (Никаноров, 2000). Высокое содержание Fе отмечено в воде озера Семеновское (более 200 мкг/л). Наименьшие концентрации Fe отмечаются в озерах, характеризующихся наибольшим загрязнением, - Ледовое и Южное, а также в оз. Среднее. Вода загрязненных озер (Ледовое и Южное) характеризуются высокими 
значениями $\mathrm{pH}$, при которых растворимость железа резко уменьшается. Растворимость гидрооксида трехвалентного железа при увеличении рН с 6 до 8 уменьшается на четыре порядка (Беус и др., 1976). При поступлении вод поверхностного стока в озера со слабощелочными условиями (значения $\mathrm{pH}$ находятся в пределах от 7.8 до 8.4) происходит выпадение в осадок гидрооксидов $\mathrm{Fe}(\mathrm{III})$ и поступление их в донные отложения (Даувальтер, Ильяшук, 2007). Во всех исследуемых городских озерах содержание Fe выше, чем среднее содержание в озерах водосбора Баренцева моря (Базова, 2017) и Северной Фенноскандии (Skjelkvåle et al., 2001).

Таблица 3. Средние концентрации (мкг/л) микроэлементов в воде озер Мурманска и фоновых озер (Базова, 2017; Skjelkvåle et al., 2001); нпо - ниже предела обнаружения.

Table 3. Average concentrations $(\mu \mathrm{g} / 1)$ of trace elements in water of the Murmansk lakes and background lakes (Bazova, 2017; Skjelkvåle et al., 2001); нпо - below detection limit.

\begin{tabular}{|c|c|c|c|c|c|c|c|}
\hline \multirow{2}{*}{ Элемент } & \multicolumn{5}{|c|}{ Озеро } & \multirow{2}{*}{$\begin{array}{c}\text { Базова, } \\
2017\end{array}$} & \multirow{2}{*}{$\begin{array}{l}\text { Skjelkvåle } \\
\text { et al., } 2001\end{array}$} \\
\hline & Семеновское & Среднее & Окуневое & Ледовое & Южное & & \\
\hline $\mathrm{Li}$ & 0.70 & 0.98 & 0.92 & 3.42 & 1.51 & 0.72 & 0.17 \\
\hline B & 6.9 & 13.3 & 9.5 & 34.3 & 41.9 & 1.74 & 1.41 \\
\hline $\mathrm{Al}$ & 37 & 60 & 55 & 28 & 24 & 31 & - \\
\hline V & 1.69 & 3.43 & 2.98 & 1.24 & 0.91 & 0.67 & $<0.3$ \\
\hline $\mathrm{Mn}$ & 36.3 & 9.7 & 14.8 & 13.8 & 14.2 & 2.09 & 3.43 \\
\hline $\mathrm{Fe}$ & 203 & 75 & 265 & 87 & 64 & 47 & 61 \\
\hline Co & 0.13 & 0.10 & 0.22 & 0.90 & 0.18 & 0.47 & 0.05 \\
\hline $\mathrm{Ni}$ & 2.91 & 6.79 & 8.99 & 10.80 & 5.93 & 1.06 & 0.33 \\
\hline $\mathrm{Cu}$ & 2.49 & 2.56 & 3.59 & 4.88 & 3.05 & 0.94 & 0.41 \\
\hline $\mathrm{Zn}$ & 2.47 & 1.03 & 6.40 & 7.34 & 2.50 & 1.66 & 1.70 \\
\hline As & 0.28 & 0.27 & 0.20 & 0.81 & 0.29 & 0.33 & - \\
\hline $\mathrm{Br}$ & 15.9 & 25.8 & 16.2 & 58.6 & 53.7 & 2.03 & - \\
\hline $\mathrm{Rb}$ & 2.65 & 4.79 & 2.34 & 7.75 & 4.60 & 1.07 & 0.49 \\
\hline $\mathrm{Sr}$ & 60.3 & 104.6 & 59.8 & 230.3 & 177.7 & 7.6 & 5.91 \\
\hline $\mathrm{Ba}$ & 17.6 & 15.8 & 20.3 & 54.3 & 71.1 & 5.08 & 3.08 \\
\hline Mo & 0.14 & 0.20 & 0.11 & 0.62 & 0.26 & 0.55 & $<0.04$ \\
\hline $\mathrm{Cd}$ & нпо & 0.18 & 0.56 & нпо & 0.22 & 0.36 & $<0.02$ \\
\hline $\mathrm{Pb}$ & нпо & 14.8 & 20.7 & 0.21 & 15.4 & 0.47 & 0.18 \\
\hline U & 0.13 & 0.02 & 0.03 & 0.24 & 0.10 & 1.01 & 0.041 \\
\hline
\end{tabular}

Наименьшее содержание $\mathrm{Mn}$, также как и $\mathrm{Fe}$, отмечено в оз. Среднее, а также в озерах, характеризующихся наибольшим загрязнением (Ледовое и Южное), а в оз. Семеновское зафиксировано наибольшее содержание $\mathrm{Mn}$ (табл. 3). При значениях $\mathrm{pH}$, характерных для поверхностных вод, окисление марганца протекает довольно медленно (Никаноров, 2000). Поэтому при попадании в водоемы $\mathrm{Fe}^{2+}$ и $\mathrm{Mn}^{2+}$ сначала идет окисление и осаждение $\mathrm{Fe}$, и лишь потом $\mathrm{Mn}$. Во всех исследуемых городских озерах содержание Мn выше, чем среднее содержание в фоновых озерах (Базова, 2017; Skjelkvåle et al., 2001).

Содержание $\mathrm{Sr}$ в воде озер Ледовое и Южное максимальное среди исследуемых озер и более чем на порядок превышает среднее содержание в фоновых озерах (табл. 3). Повышенные содержания $\mathrm{Sr}$, возможно, связаны с его поступлением при разрушении элементов зданий и сооружений из строительных материалов, содержащих высокие концентрации Sr. Довольно большое количество $\mathrm{Sr}$ зафиксировано также в воде оз. Среднее, вызванное переносом морских аэрозолей, содержащих повышенные концентрации Sr. Аналогичная закономерность выявляется и в распределении других щелочных металлов Li и $\mathrm{Rb}$, а также щелочноземельного Вa. Во всех исследуемых городских озеpax содержание $\mathrm{Sr}, \mathrm{Li}, \mathrm{Rb}$ и Ва выше, чем среднее содержание в в фоновых озерах (табл. 3). Высокие значения коэффициента корреляции концентраций $\mathrm{Sr}, \mathrm{Li}$ и $\mathrm{Rb}(\mathrm{r}=0.87-0.99)$, и в меньшей степени $\mathrm{Ba}(\mathrm{r}=0.67-0.83)$, также как и $\mathrm{B}$ и $\mathrm{Br}(\mathrm{r}=0.88-0.99$ при $\mathrm{p}<0.01)$, с содержанием главных кати- 
онов $\left(\mathrm{Ca}^{2+}, \mathrm{Mg}^{2+}, \mathrm{Na}^{+}\right.$и $\left.\mathrm{K}^{+}\right)$подтверждает вывод о поступлении щелочных и щелочноземельных металлов из одних источников, которыми являются выветривание строительных материалов на территории города, использование реагентов для противогололедной обработки городских дорог и морские аэрозоли.

Наибольшие содержания тяжелых металлов $\mathrm{Ni}, \mathrm{Cu}, \mathrm{Zn}, \mathrm{Co}, \mathrm{As}$ и Мо отмечены в воде оз. Ледовое (табл. 3). В воде оз. Окуневое, одном из относительно чистых среди изученных озер, отмечено наибольшее содержание $\mathrm{Cd}$ и $\mathrm{Pb}$. За редким исключением, содержание всех тяжелых металлов в воде городских озер выше, чем среднее содержание в фоновых озерах (табл. 3). Наибольшее содержание V было обнаружено в воде озер Среднее и Окуневое (табл. 3), ближе всех расположенных к Мурманской ТЭЦ, на которой в качестве топлива используется мазут, содержащий повышенные концентрации этого элемента. Возможно, наибольшие содержания $\mathrm{Cd}$ и $\mathrm{Pb}$ в оз. Окуневое также связаны с выбросами Мурманской ТЭЦ. В глобальном масштабе главным источником выбросов тяжелых металлов продолжает оставаться стационарное сжигание ископаемого топлива.

\section{Заключение}

Установлено, что значительно увеличились значения рН воды озер Мурманска по сравнению с фоновыми, что связано с выветриванием и разрушением элементов городских зданий и сооружений и поступлением в повышенных содержаниях главных катионов. По этой же причине, а также за счет поступления морских аэрозолей, в воде городских озер увеличивается содержание других щелочных ( $\mathrm{Li}$ и $\mathrm{Rb}$ ) и щелочноземельных ( $\mathrm{Sr}$ и $\mathrm{Ba}$ ) металлов, а также $\mathrm{B}$ и $\mathrm{Br}$, значительно превышающее средние концентрации в фоновых озер. В воде городских озер значительно увеличилось содержание соединений азотной группы, особенно аммоний-иона, что говорит о формировании восстановительной обстановки, губительно действующей на гидробионты. Наиболее загрязненным среди исследованных озер является Ледовое, в меньшей степени Южное, характеризующиеся наибольшим содержанием вышеперечисленных показателей, а также многих тяжелых металлов. В то же время, в этих озерах отмечается наименьшее содержание органических веществ в связи с угнетением биологических процессов. В озерах Ледовое и Южное наблюдается снижение содержания Fе и Mn вследствие увеличения величины рН и образования в этих условиях малорастворимых гидрооксидов. Дополнительным источником загрязнения городских озер является Мурманская ТЭЦ, на которой в качестве топлива используется мазут, что проявляется в увеличении содержания V, a также $\mathrm{Cd}$ и $\mathrm{Pb}$, в воде озер.

Исследование выполнено за счет гранта Российского научного фонда (проект № 19-77-10007).

\section{Литература}

1. Алекин О.А. Основы гидрохимии. Л.: Гидрометеоиздат, 1970. 444 с.

2. Базова М.М. Особенности формирования элементного состава вод Кольского Севера в условиях функционирования горнорудных производств // Геохимия. 2017. № 1. С. 92-106.

3. Беус А.А., Грабовская Л.И., Тихонова Н.В. Геохимия окружающей среды. М.: Недра. 1976. 248 с.

4. Большаков Г.Ф. Азоторганические соединения нефти. Новосибирск. Изд-во: Наука. 1988.

5. Даувальтер В.А., Ильяшук Б.П. Условия образования железо-марганцевых конкреций в донных отложениях озер в пределах Балтийского кристаллического щита // Геохимия. 2007. № 6. С. 680-684.

6. Кашулин Н.А., Сандимиров С.С., Даувальтер В.А., Кудрявцева Л.П., Терентьев П.М., Денисов Д.Б., Валькова С.А. Аннотированный экологический каталог озер Мурманской области (Восточная часть. Бассейн Баренцева моря). В 2 ч. Апатиты. Изд-во: Кольского НЦ РАН. 2010. Ч. 1. 249 с., Ч. 2.128 с.

7. Моисеенко Т.И., Даувальтер В.А., Лукин А.А., Кудрявцева Л.П., Ильяшук Б.П., Ильяшук Е.А., Сандимиров С.С., Каган Л.Я., Вандыш О.И., Шаров А.Н., Шарова Ю.Н., Королева И.М. Антропогенные модификации экосистемы озера Имандра. Москва. Изд-во: Наука. 2002. 403 с.

8. Моисеенко Т.И., Дину М.И., Гашкина Н.А., Кремлева Т.А. Формы нахождения металлов в природных водах в зависимости от их химического состава // Водные ресурсы. 2013. Т. 40. № 4. С. 375-385.

9. Никаноров А.М. Гидрохимия. С.-Пб.: Гидрометеоиздат. 2000. 444 с.

10. Skjelkvåle B.L., Andersen T., Fjeld E., Mannio J., Wilander A., Johansson K., Jensen J.P., Moiseenko T.I. Heavy Metal Surveys in Nordic Lakes; Concentrations, Geographic Patterns and Relation to Critical Limits // AMBIO. 2001. V. 30. P. 2-10. 